\title{
The surgical and interventional hybrid era: Experiences from China
}

\author{
Shengshou $\mathrm{Hu}, \mathrm{MD}, \mathrm{MSc}$
}

It was the best of times, it was the worst of times...we had everything before us, we had nothing before us, we were all going direct to Heaven, we were all going direct the other way.

Charles Dickens, A Tale of Two Cities, 1859

It is estimated that more than 230 million Chinese have some form of cardiovascular disease, and this number is projected to increase by $50 \%$ between 2010 and $2030 .{ }^{1}$ The number of cardiac surgical procedures is therefore increasing dramatically in China, with an annual volume of nearly 160,000 cases. Chinese cardiac surgeons, however, are confronted by the same challenges as their Western counterparts. Catheter-based procedures were introduced in China in the 1980s, along with the opening of New China. Driven by patient demand and market forces, some procedures were quickly popularized across the country, and the traditional open-chest surgical approaches gradually receded. The percutaneous transcatheter aortic valve implantation procedure has emerged as an attractive option for critically ill patients, ${ }^{2}$ and recently the first case of percutaneous transcatheter aortic valve implantation was successfully performed by the interventional cardiologists in Fuwai hospital in Beijing. Although the current available evidence is inadequate to determine the role of percutaneous transcatheter aortic valve implantation in the treatment of heart valve disease, it is a new challenge to surgical aortic valve replacement.

As a developing country, China has had an extremely rapid pace of economic growth in the last 30 years. With the ongoing improvement in the Medicare system, more patients can afford to undergo heart surgery, and the volume of cardiac surgical procedures per program has steadily increased $15 \%$ to $20 \%$ annually. Although many minimally invasive technologies have been introduced and disseminated to the cardiac surgical community of China, less invasive percutaneous interventional therapy is an attractive option for many patients. The incomplete revascularization of the myocardium, the high stent restenosis rate, and other

\footnotetext{
From the Department of Surgery, Cardiovascular Institute and Fuwai Hospital, Chinese Academy of Medical Sciences and Peking Union Medical College, Beijing, China.

Disclosures: Author has nothing to disclose with regard to commercial support.

Received for publication Feb 19, 2011; accepted for publication March 3, 2011; available ahead of print April 8, 2011.

Address for reprints: Shengshou Hu, MD, MSc, Department of Cardiac Surgery, Cardiovascular Institute and Fu Wai Hospital,167 Beilishi Rd, Beijing 100037, China (E-mail: huss@vip.sohu.com).

J Thorac Cardiovasc Surg 2011;141:1339-41

$0022-5223 / \$ 36.00$

Copyright (c) 2011 by The American Association for Thoracic Surgery

doi: 10.1016/j.jtcvs.2011.03.007
}

device-related complications, however, remain problems for interventional cardiologists. Therefore, the barriers between disciplines are being lowered, and a multidisciplinary approach should be used when selecting the best therapy for patients. In 1996, Angelini and associates ${ }^{3}$ combined the $^{-}$ techniques of percutaneous coronary intervention and minimally invasive direct coronary artery bypass grafting to treat multivessel coronary artery disease. It was the first time that a hybrid approach to integrate interventional and surgical technology was used for patient care. During the past decade, the hybrid approach has actually practiced the principle of "Patients Always First" by providing incremental benefits to patients with the best of combined therapies.

With the development of devices and real-time imaging, setting up a hybrid operating room to perform both surgery and catheter-based therapy has become a reality. With the aid of image-guided technology, surgeons can now use various interventional devices. Surgeons know more about the anatomy, have no limits for access route, have operative perception, and, most importantly, can use the traditional surgical technology simultaneously. We have witnessed the introduction of the hybrid concept and its booming development across China. Now, more than 30 hybrid operating rooms are in clinical practice across China, and surgeons from China have accomplished many successes in the field of hybrid cardiac surgery, including procedures in congenital heart disease, coronary artery bypass surgery, and aortic surgery, as summarized in Table 1. ${ }^{4-10}$

\section{CORONARY ARTERY DISEASE}

Fuwai hospital has the largest cardiac surgical program in China and all of Asia. As early as 1997, Dr Gao, the former president of Chinese Association of Cardiology, and I worked together to use videothoracoscopy-assisted minimally invasive direct coronary artery bypass grafting and angioplasty to treat multivessel coronary artery disease. ${ }^{11}$ The first hybrid experience by Chinese physicians was performed sequentially between the catheter laboratory and the traditional operating room. In 2007, the first true hybrid operating room in China was established at Fuwai Hospital and is now the hospital's busiest operating room (Figure 1).

The past decade has brought developments in both percutaneous coronary intervention and coronary artery bypass grafting. Both interventions have witnessed significant technological advances, in particular the use of drugeluting stents in percutaneous coronary intervention and increased use of arterial grafts in coronary artery bypass grafting. The bifurcation lesion, total occlusion of the left 
TABLE 1. Selected publications by Chinese surgeons in the field of hybrid cardiac surgery

\begin{tabular}{|c|c|c|c|}
\hline Reference & Center & Year & Major topic \\
\hline Zhang et $\mathrm{al}^{4}$ & Fuwai & 2007 & $\begin{array}{l}\text { Hybrid therapy for } \\
\text { neonatal PAIVS }\end{array}$ \\
\hline Zhang et $\mathrm{al}^{5}$ & Fuwai & 2007 & $\begin{array}{l}\text { Peratrial pediatric ASD } \\
\text { device closure }\end{array}$ \\
\hline $\mathrm{Li}$ et $\mathrm{al}^{6}$ & Shanghai Chest & 2008 & $\begin{array}{l}\text { VSD device closure } \\
\text { through lower } \\
\text { ministernotomy }\end{array}$ \\
\hline Gang et $\mathrm{al}^{7}$ & West China & 2008 & $\begin{array}{c}\text { Open-chest perventricular } \\
\text { device closure of VSD }\end{array}$ \\
\hline Xing et $\mathrm{al}^{8}$ & Qingdao Children & 2010 & $\begin{array}{l}\text { Multicenter trials for } \\
\text { perventricular VSD } \\
\text { device closure }\end{array}$ \\
\hline Hu et $\mathrm{al}^{9}$ & Fuwai & 2010 & $\begin{array}{l}\text { Comparison of off-pump } \\
\text { coronary artery bypass } \\
\text { grafting with hybrid } \\
\text { coronary } \\
\text { revascularization }\end{array}$ \\
\hline Chen et $\mathrm{al}^{10}$ & Fujian Union & 2010 & $\begin{array}{l}\text { Novel triple-branched } \\
\text { stent graft placement } \\
\text { technique for acute } \\
\text { type A aortic dissection }\end{array}$ \\
\hline
\end{tabular}

PAIVS, Pulmonary atresia and intact ventricular septum; $V S D$, ventricular septal defect; $A S D$, atrial septal defect.

anterior descending coronary artery, and left main coronary artery disease, however, are still very challenging for cardiologists. Because of the superb long-term patency of grafted left internal thoracic artery, cardiologists perform the "protected" angioplasty after the surgeon has finished the left internal thoracic artery-left anterior descending coronary artery anastomosis. Encouraged by the initial hybrid experiences, a new 1-stop strategy has been applied in Fuwai Hospital for selected patients with coronary artery disease since 2007. Now more than 104 patients have successfully undergone this one-stop hybrid therapy. ${ }^{9}$ Because of an aging population and a higher incidence of coronary artery disease, multivessel revascularization is increasing in China. In a Chinese coronary artery disease database study involving a total of 3720 patients, left main coronary, bifurcation lesion, and total occlusion of left anterior descending coronary artery accounted for $20 \%$ of the coronary artery disease seen in Chinese patients. ${ }^{12}$

\section{CONGENITAL HEART DISEASE}

Congenital heart disease is the leading birth defect in China. Congenital heart disease accounts for more than $50 \%$ of surgical volume in most cardiac surgery programs in China at Fuwai hospital, and more than 4500 patients with congenital heart disease were operated on in 2010. In our hybrid experiences for congenital heart disease, we have developed a new hybrid approach for neonates with pulmonary atresia with intact ventricular septum ${ }^{4}$ and young children with atrial septal defect with partial anomalous pulmonary venous connection. As of this writing, 30 neonates and infants with pulmonary atresia and intact ventricular septum and favorable anatomy have undergone successful open-chest perventricular balloon perforation and valvuloplasty with or without modified Blalock-Taussig shunt placement. We have also designed a new one-stop strategy for tetralogy of Fallot and pulmonary atresia with major aortopulmonary collateral arteries. ${ }^{13}$ Major aortopulmonary collateral arteries were identified in $76 \%$ of the patients with tetralogy of Fallot or pulmonary atresia, and $82 \%$ of these underwent successful coil implantation. The surgeons then opened the chest and started regular repair immediately after the cardioangiography.

\section{VASCULAR SURGERY}

The hybrid operating room is the vascular surgeon's favorite operating room. The concept of endovascular surgery has expanded to the treatment of thoracic aortic aneurysms
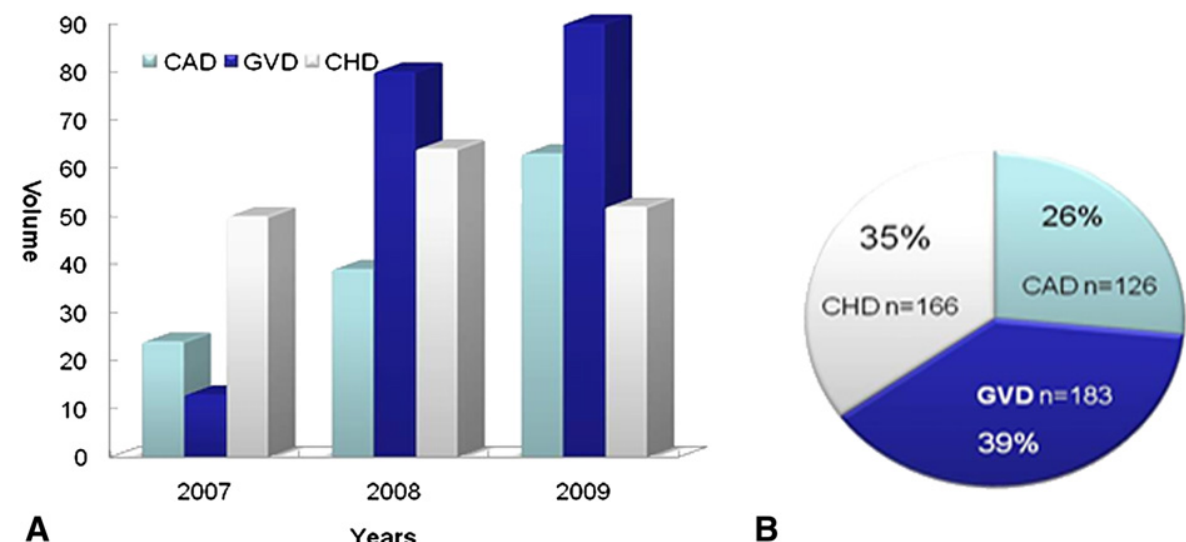

B

FIGURE 1. Distribution of various types of hybrid surgery in Fuwai hospital, Beijing, China. A, Numbers of cases of 3 major heart diseases treated in the hybrid operating room during the past 3 years. B, The distribution of these 3 diseases among the total 475 patients. $C A D$, Coronary artery disease; GVD, great vessel disease; $C H D$, congenital heart disease. 


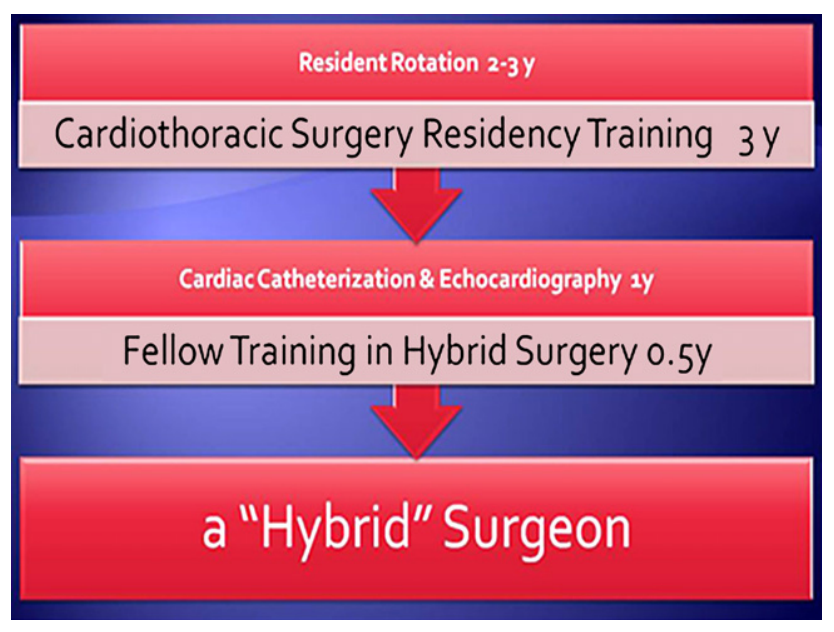

FIGURE 2. A proposed training program for the young hybrid cardiac surgeon in China.

and aortic dissection. The number of cases of great vessel disease repair performed in the hybrid operating room in our center has increased dramatically during the past 3 years (Figure 1). According to the 2005 Annual Report on Cardiovascular Disease in China, ${ }^{14} 160$ million people in China have hypertension; the incidence of aortic dissection could be as high as 20 to 50 per million population. With the aid of the hybrid approach, the mortality and morbidity of aortic surgery have been significantly reduced, and more patients with great vessel disease will benefit from hybrid surgery at their local centers in the near future.

\section{CONCLUSIONS}

Cardiac surgeons in China have many reasons to promote hybrid surgery. First, they are not mere guests in the catheter laboratory to assist the interventional cardiologist. Since the catheter-based training program was initiated for surgeons 5 years ago, surgeons have been free to use the devices and play the lead in a hybrid procedure. Second, the high cost of catheter-based therapy has often forced families to be referred to cardiac surgeons for their critically ill children with congenital heart disease, and traditionally in China it is the cardiac surgeon, not the pediatric cardiologist, who first sees the patient with complex congenital heart disease. Finally, a positive cycle among surgeons, cardiologists, and local manufacturers has formed during the last 5 years. In 2008, the National Center for Cardiovascular Diseases hosted the first International Symposium on Hybrid Approach to Heart Diseases. For the first time, international and domestic surgeons and interventionalists discussed the same case to choose the best therapeutic option for the patient. More than 1000 local attendees were present, and since then hybrid procedures have been a hot topic at every major heart meeting in China.
Surgeons must experience the initial segment of a learning curve to get acquainted with the new hybrid protocols and with their new colleagues from the interventional community. As a result, new training programs have begun to train the new hybrid surgeon (Figure 2). The first young surgeons from Fuwai Hospital have finished their overseas training in a prestigious heart center in Western Europe, and since returning to China they have passed their examinations and are now licensed to perform interventional therapy.

Hybrid cardiac surgery has opened up a whole new perspective for the cardiac surgeon. It is time for us to make the change. Surgeons should know and understand the development of new interventional and hybrid technology, and furthermore they should have the courage to leave their own comfort zone. The success of hybrid surgery in China indicates that a bright future lies ahead for our patients as well as the cardiac surgical community.

\section{References}

1. Moran A, Gu D, Zhao D, Coxson P, Wang YC, Chen CS, et al. Future cardiovascular disease in China: Markov model and risk factor scenario projections from the coronary heart disease policy model-China. Circ Cardiovasc Qual Outcomes. 2010;3:243-52.

2. Masson JB, Kovac J, Schuler G, Ye J, Cheung A, Kapadia S, et al. Transcatheter aortic valve implantation: review of the nature, management, and avoidance of procedural complications. JACC Cardiovasc Interv. 2009;2:811-20.

3. Angelini GD, Wilde P, Salerno TA, Bosco G, Calafiore AM. Integrated left small thoracotomy and angioplasty for multivessel coronary artery revascularisation. Lancet. 1996;347:757-8.

4. Zhang H, Li SJ, Li YQ, Wang H, Hu SS. Hybrid procedure for the neonatal management of pulmonary atresia with intact ventricular septum. J Thorac Cardiovasc Surg. 2007;133:1654-6.

5. Zhang H, Li SJ, Li YQ, Wang H, Hu SS. Open-chest device closure for the minimally invasive management of atrial septal defect in young children. Heart Surg Forum. 2007;10:E125-8.

6. Li F, Chen M, Qiu ZK, Lu J, Wu W. A new minimally invasive technique to occlude ventricular septal defect using an occluder device. Ann Thorac Surg. 2008; 85:1067-71.

7. Gan C, An Q, Lin K, Tang H, Lui RC, Tao K, et al. Perventricular device closure of ventricular septal defects: six months results in 30 young children. Ann Thorac Surg. 2008;86:142-6

8. Xing Q, Pan S, An Q, Zhang Z, Li J, Li F, et al. Minimally invasive perventricular device closure of perimembranous ventricular septal defect without cardiopulmonary bypass: multicenter experience and mid-term follow-up. J Thorac Cardiovasc Surg. 2010;139:1409-15.

9. Hu SS, Li Q, Gao PX, Xiong H, Zheng Z, Li LH, et al. Simultaneous hybrid revascularization versus off-pump coronary artery bypass for multivessel coronary artery disease. Ann Thorac Surg. 2011;91:432-8

10. Chen LW, Dai XF, Lu L, Zhang GC, Cao H. Extensive primary repair of the thoracic aorta in acute type a aortic dissection by means of ascending aorta replacement combined with open placement of triple-branched stent graft: early results. Circulation. 2010;122:1373-8.

11. Gao R, Hu S, Zheng Z, Yang Y, Qiao S, Qin X, et al. "Hybrid” revascularization video-thoracoscopy assisted MIDCAB combined with angioplasty. $J$ Invasive Cardiol. 2001;13:257-9; discussion 266-70.

12. Li Y, Zheng Z, Xu B, Zhang S, Li W, Gao R, et al. Comparison of drug-eluting stents and coronary artery bypass surgery for the treatment of multivessel coronary disease: three-year follow-up results from a single institution. Circulation 2009; 119:2040-50.

13. Hu S. One-stop hybrid approach for cardiovascular disease: from conception to practice. Ann Thorac Cardiovasc Surg. 2008;14:345-6.

14. Hu S, Kong L, Hypertension. In: 2005 Report on cardiovascular diseases in China. Beijing, China: Chinese Macropaedia Press; 2006:84-97. 